EUROPEAN ORGANIZATION FOR NUCLEAR RESEARCH

European Laboratory for Particle Physics

\title{
The Influence of Air Exposures and Thermal Treatments on the Secondary Electron Yield of Copper
}

\author{
I. Bojko ${ }^{\mathrm{a}, 1}$, N. Hilleret ${ }^{\mathrm{a}}$ and Ch. Scheuerlein
}

\begin{abstract}
The variation of the secondary electron yield (SEY) of sputter-cleaned OFHC-copper has been studied as a function of air exposure duration at room temperature. After short air exposures of some seconds the maximum SEY $\left(\delta_{\mathrm{MAX}}\right)$ of clean copper is reduced from 1.3 to less than 1.2, due to the oxidation of the copper surface. Prolonged air exposure increases the SEY steadily until, after about 8 days of atmospheric exposure, $\delta_{\mathrm{MAX}}$ is higher than 2 .

Air exposures at higher temperatures have been found to be effective in reducing the SEY of technical copper surfaces. A 5-minute air exposure of copper at $350^{\circ} \mathrm{C}$ followed by a $350^{\circ} \mathrm{C}$ bake-out under vacuum reduces $\delta_{\text {мAX }}$ to about 1.05, which is lower than the value of pure copper and that of $\mathrm{Cu}_{2} \mathrm{O}$.
\end{abstract}

a LHC Division, Vacuum Group, CERN, Geneva, Switzerland
b EST Division, Surfaces and Materials Group, CERN, Geneva Switzerland
1 Present address: MPI,-Institut für Plasmaphysik, D-85748 Garching

Journal for Vacuum Science and Technology A,

May/June, 2000

\author{
Administrative Secretariat \\ LHC Division \\ CERN \\ CH - 1211 Geneva 23 \\ Switzerland \\ Geneva, 11 April 2000
}




\section{Introduction}

The performance of particle accelerators may be severely hampered by resonant multiplication of secondary electrons (multipacting). Multipacting is frequently observed in accelerating radio-frequency (RF) cavities ${ }^{1}$ and it can also occur in the beam vacuum system of particle accelerators (beam induced multipacting). ${ }^{2}$

Apart from the resonance conditions between the driving electric field and the geometry of the vacuum chamber, multipacting is strongly influenced by the secondary electron yield (SEY), i.e. the number of emitted electrons per incident electron, of the involved surfaces. Therefore, it is important to know the SEY of all materials used in accelerator vacuum systems in which multipacting can occur.

Copper is used in RF cavities to coat auxiliary equipment like power couplers and it is also a candidate surface coating for the internal beam vacuum surfaces of CERNs next accelerator, the Large Hadron Collider (LHC). The SEY of pure copper can be found in literature. However, secondary electron (SE) emission is a surface sensitive process, which is strongly influenced by surface contamination occuring for instance during air exposures.

In this paper measurements are presented, which show the variation of the SEY of initially sputter-cleaned OFHC-copper as a function of air exposure time.

Since the SEY of technical metal surfaces is usually significantly higher than the SEY of the corresponding pure metals, some kind of in-situ treatment (conditioning) is often required in order to reduce SE emission such that multipacting can be avoided.

In this context the influence of different heat treatments on the SEY of technical copper surfaces has been studied. Tested heat treatments are ordinary bake-outs at various temperatures and air exposures at $150^{\circ} \mathrm{C}$ and $350^{\circ} \mathrm{C}$ followed by a bake-out under vacuum.

\section{Experimental}

Throughout this paper all electrons emitted upon primary electron (PE) irradiation, regardless their origin, are called secondary electrons (SE). The secondary electron yield (SEY) is defined as the number of all emitted SE per incident PE. The maximum SEY $\left(\delta_{\text {MAX }}\right)$, the PE energy $E_{\text {MAX }}$ at which $\delta_{\text {MAX }}$ occurs and the PE energy $E_{1}$ at which the SEY exceeds unity are characteristic values of the SEY versus PE-energy $\left(E_{P}\right)$ spectrum.

\section{A Experimental set-up}

The measurements were carried out with the apparatus shown in principle in Figure 1. It consists basically of an electron gun, a collector for the emitted electrons, a revolving sample holder and the vacuum equipment that is necessary to achieve a base pressure in the $10^{-8} \mathrm{~Pa}$ region.

The revolving sample holder allows charging the experiment with up to 14 samples. The sample dimensions are $30 \mathrm{~mm} \times 20 \mathrm{~mm} \times 2 \mathrm{~mm}$. 
All reported SEY measurements were carried out at normal PE angle of incidence. The $\mathrm{PE}$ are accelerated in the electron gun to energies between $60 \mathrm{eV}$ and $3 \mathrm{keV}$. They are then guided by electrostatic deflection plates through a hole in the collector and onto the sample. Before the measurements a specially developed software optimises the voltages of the electrostatic $\mathrm{e}^{-}$gun optics in order to have the maximum possible beam current reaching the samples at each $\mathrm{PE}$ energy.

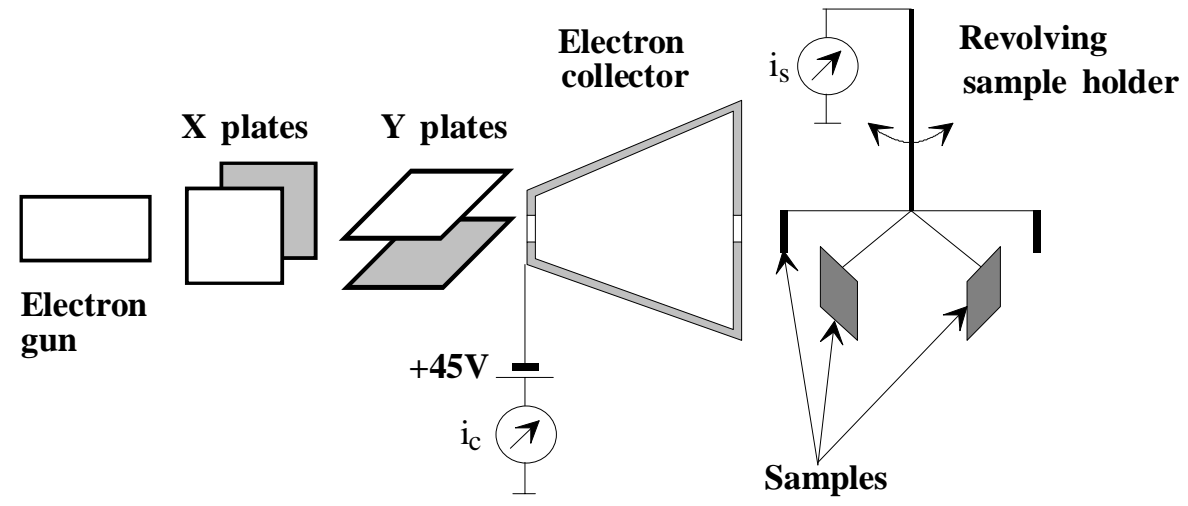

Figure 1: Experimental set-up for the measurement of the SEY $\delta$

The collector is biased to $+45 \mathrm{~V}$ with respect to ground in order to capture all SE, which are emitted by the sample and also to re-capture SE, which are emitted by the collector itself. Only a small fraction of backscattered electrons can escape.

Sample-to-ground current $i_{s}$ and collector current $i_{c}$ are measured simultaneously by two current amplifiers (Keithley 427) and the SEY $\delta$ is calculated as follows:

$$
\delta=\frac{i_{c}}{i_{c}+i_{s}}
$$

where the sum of the sample current $i_{s}$ and the collector current $i_{c}$ represents the beam current $i_{b}$.

$$
i_{b}=i_{s}+i_{c}
$$

The SEY of materials can be modified by electron irradiation, particularly if the surface is covered by adsorbed foreign species. ${ }^{3,4}$ Therefore, the instrument has been designed to allow measuring the SEY using PE doses as low as possible. The PE current is typically $5 \cdot 10^{-9} \mathrm{~A}$, the required pulse length for one measurement is $30 \mathrm{~ms}$ and the beam area is about $1 \mathrm{~mm}^{2}$. The total electron dose for the 60 measurements, which are carried out at different PE energies, is about $10^{-8} \mathrm{C} / \mathrm{mm}^{2}$.

\section{B Sample preparation}

The investigated samples are made of polycrystalline OFHC copper $(99.99 \%+\mathrm{Cu})$ sheet. Before the measurements all samples were cleaned following the standard chemical cleaning procedure for vacuum equipment at CERN, which is described elsewhere. ${ }^{5}$ Copper samples obtained after this cleaning are referred to as 'as-received' copper. 
'Clean' copper samples were obtained by in-situ sputter-etching of as-received copper samples during an argon glow discharge lasting $15 \mathrm{~min}$ (sample bias $-1 \mathrm{kV}$ with respect to the grounded vacuum chamber, $5 \mathrm{~Pa}$ argon pressure, ion current $25 \mathrm{~mA}$ ). The obtained copper surfaces are referred to as sputter-cleaned surfaces. The maximum SEY $\delta_{\text {MAX }}$ of such sputter-cleaned copper surfaces varied between 1.3 and 1.4. The value reported for atomically clean copper is $1.3 .^{6}$

Baking the as-received copper samples was realised during a bake-out of the whole experimental chamber. The samples were thus heated by radiation from the hot chamber walls. Unless explicitly mentioned bake-outs were carried out under vacuum. In some cases the samples were also heated in air. This procedure is referred to as 'air-baking'.

The given bake-out temperatures are those of the vacuum chamber. The true sample temperatures could have been slightly lower, in particular during air-baking, where the chamber was vented to atmospheric pressure.

\section{Gas exposures}

Air exposure is expressed in minutes or days of ordinary laboratory air. An average temperature of $20^{\circ} \mathrm{C}$ and a mean relative humidity of $60 \%$ of the laboratory air are estimated.

The samples were exposed to air either inside or outside the vacuum chamber. Short air exposures lasting a few minutes could only be realised inside the chamber, i.e. the chamber was vented with air to atmospheric pressure. After the chosen exposure time the venting valve was closed and the chamber was again evacuated. Air exposures of hot samples (air-baking) were always carried out inside the vacuum chamber.

For air exposures outside the vacuum chamber the sample holder was dismounted from the experimental chamber and placed in the laboratory together with the samples. Dismounting the sample holder lasted about 20 min during which the samples remained inside the chamber. Unless explicitly mentioned, the reported air exposures were realised outside the vacuum chamber.

Oxygen exposures are expressed in Langmuir $\left(1 \mathrm{~L}=1 \mathrm{~s} \cdot 1.33 \cdot 10^{-4} \mathrm{~Pa}\right)$. At low injection pressures up to $10^{-4} \mathrm{~Pa}$ oxygen was injected in the vacuum chamber 'dynamically', i.e., oxygen was continuously injected through a variable leak valve as the vessel was pumped by a sputter ion pump.

To expose the copper samples to higher doses in a reasonable time all pumps were valved off and oxygen was injected at $100 \mathrm{~Pa}$. Afterwards nitrogen was injected into the chamber so that the mixture could be safely pumped via a turbomolecular pump.

Water vapour was produced in a separate vacuum vessel, which was filled with distilled water. This vessel was evacuated by a dry, three-stage diaphragm pump and the pressure inside this vessel was monitored with a Pirani gauge. After a short while the vapour pressure of water $\left(2.3 \cdot 10^{3} \mathrm{~Pa}\right.$ at $\left.20^{\circ} \mathrm{C}\right)$ was achieved.

The water vapour filled vessel was connected with the experimental chamber via a flexible line and a variable leak valve. Low $\mathrm{H}_{2} \mathrm{O}$ doses were exposed dynamically, i.e. 
during $\mathrm{H}_{2} \mathrm{O}$ injection the experimental chamber was continuously pumped by a turbomolecular pump. The residual gas in the experimental chamber could be analysed with a quadrupole mass spectrometer (Balzers QMG 112). Higher doses of $\mathrm{H}_{2} \mathrm{O}$ were realised by static exposure at a pressure of about $10^{3} \mathrm{~Pa}$.

\section{Results}

\section{A Gas exposures}

\section{Influence of air exposures at ambient temperature on the SEY of initially sputter- cleaned copper}

The SEY of sputter-cleaned copper changes after air exposure at ambient temperature. Exposures of a few minutes decrease $\delta_{\mathrm{MAX}}$ to about 1.2 and $\mathrm{E}_{\mathrm{MAX}}$ is shifted from about $650 \mathrm{eV}$ to less than $400 \mathrm{eV}$. However, further air exposure increases the SEY steadily as shown in Figure 2.

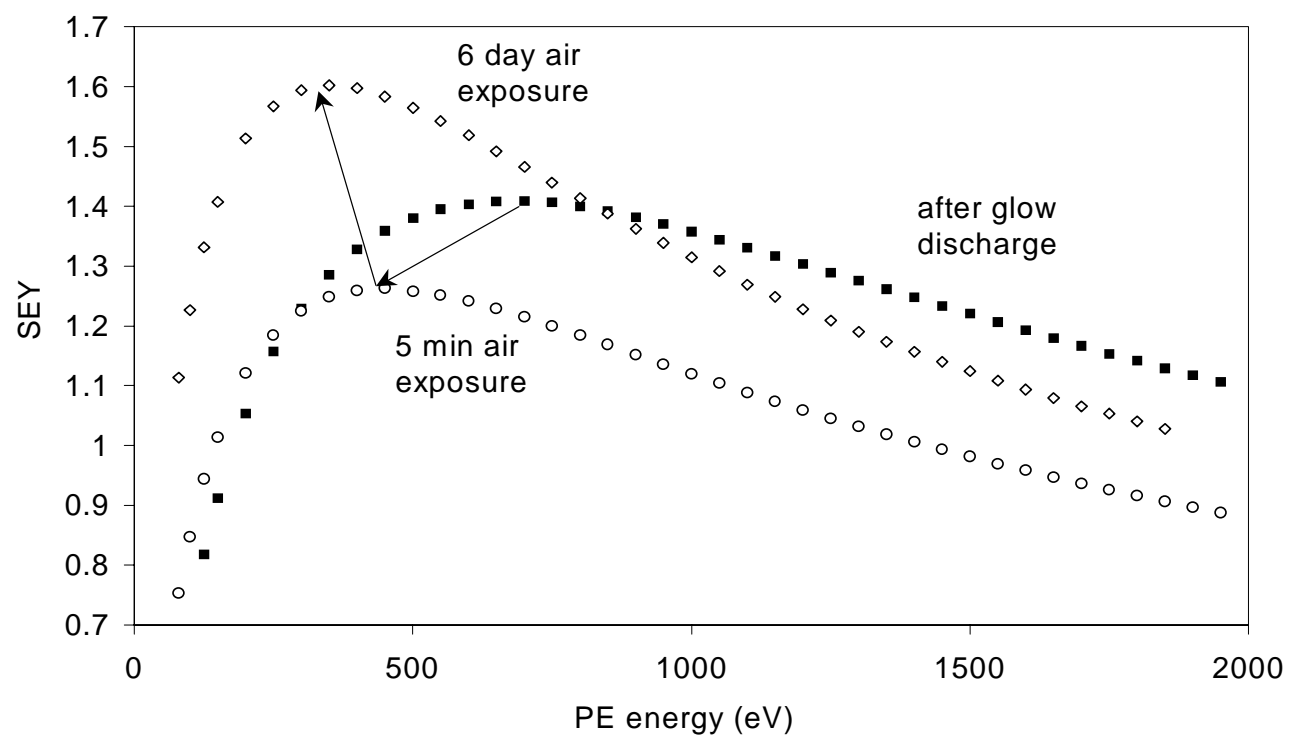

Figure 2: SEY of initially sputter-cleaned copper, after 5 minutes and 6 days of air exposure inside the vacuum vessel as a function of PE energy. The initial decrease of $\delta_{\text {MAX }}$ is characteristic for copper. With increasing air exposure time $\mathrm{E}_{\mathrm{MAX}}$ shifts to lower PE energy (the arrows indicate increasing air exposure time).

There is a significant difference in the variation of the SEY after air exposures which were realised inside and outside the vacuum chamber. Air exposure outside the chamber causes a stronger increase of the SEY than an exposure inside the chamber of the same duration. $\delta_{\text {MAX }}$ of a sputter-cleaned copper surface increases to 1.6 and 1.9 after 6 days air exposure inside and outside the experimental chamber respectively. After about 8 days air exposure outside the chamber $\delta_{\mathrm{MAX}}$ exceeds 2 and it continues to increase with air exposure time.

Dew point measurements of the air inside the experimental chamber as a function of the time after air-venting showed that the humidity inside the chamber is in the first two hours after air-venting significantly lower than in the ambient air. Afterwards the 
humidity of the air inside the chamber approaches that of the laboratory air outside the chamber (the humidity sensor was not calibrated and quantitative values can not be given). This could indicate that the humidity of the exposed air has an important influence on the SEY.

\section{Influence of $\mathrm{O}_{2}$ exposure on the SEY of initially sputter-cleaned copper}

Sputter-cleaned copper samples were exposed to different doses of pure oxygen and to pure water vapour in order to find out the reasons for the strong changes of the SEY after air exposures.

An exposure of sputter-cleaned $\mathrm{Cu}$ to $10 \mathrm{~L}$ pure oxygen does not change the SEY measurably. After $100 \mathrm{~L} \mathrm{O}_{2}$ exposure the SEY is slightly decreased and continues to decrease with increasing $\mathrm{O}_{2}$ exposure until, after $10^{9} \mathrm{~L} \mathrm{O}_{2}, \delta_{\text {MAX }}$ is below 1.2. As shown in Figure 3. $\mathrm{E}_{\mathrm{MAX}}$ shifts to lower PE energies with increasing $\mathrm{O}_{2}$ exposure.

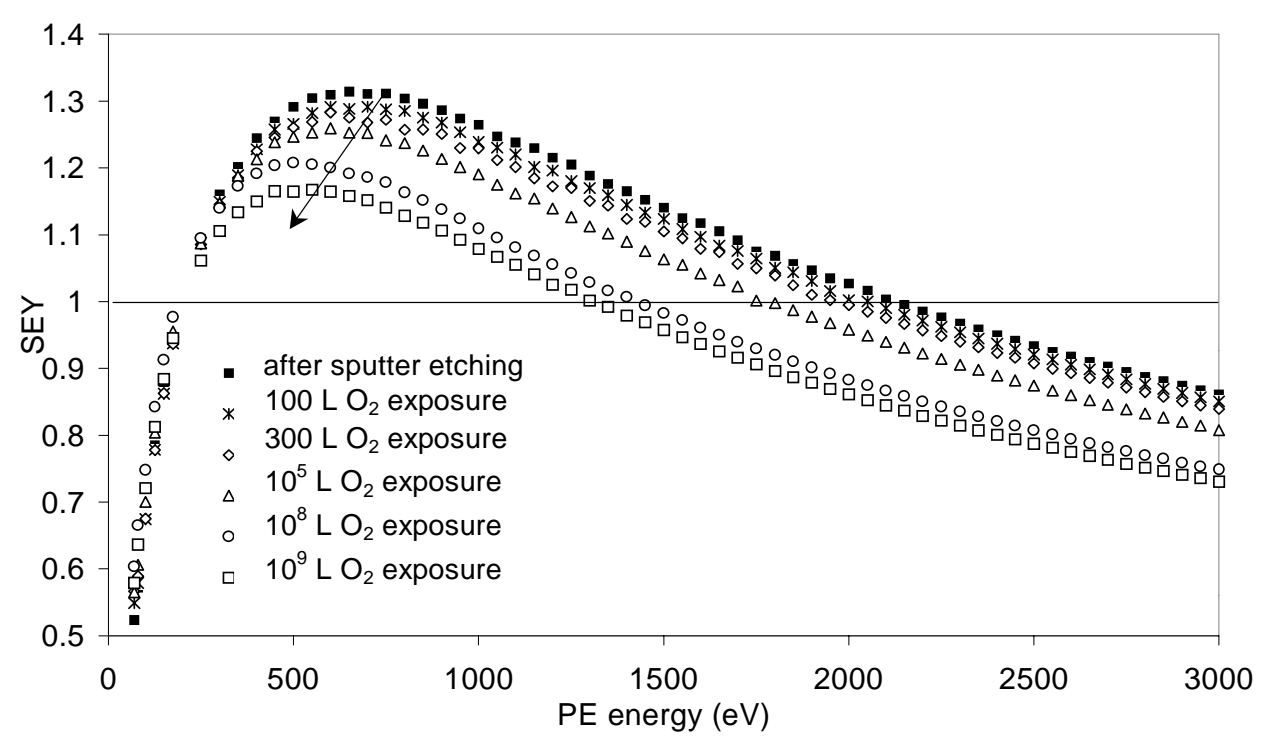

Figure 3: SEY of initially sputter-cleaned $\mathrm{Cu}$ after different doses of oxygen. The SEY decreases and $\mathrm{E}_{\mathrm{MAX}}$ shifts to lower PE energies with increasing $\mathrm{O}_{2}$ dose (the arrow indicates increasing $\mathrm{O}_{2}$ dose).

After $10^{9} \mathrm{~L} \mathrm{O}_{2}$ exposure it is assumed that the oxidation of copper at room temperature is essentially complete and that the formed oxide is essentially cuprous oxide $\left(\mathrm{Cu}_{2} \mathrm{O}\right){ }^{7}$ The $\delta_{\mathrm{MAX}}$ value for $\mathrm{Cu}_{2} \mathrm{O}$ found in literature is between 1.19 and $1.25^{6}$ which is close to the value measured after $10^{9} \mathrm{~L} \mathrm{O}_{2}$ exposure.

\section{Influence of $\mathrm{H}_{2} \mathrm{O}$ exposure on the SEY of initially sputter-cleaned copper}

Exposing in-situ sputter-cleaned copper to pure water vapour slightly increases the SEY. A $\mathrm{H}_{2} \mathrm{O}$ dose of 81 hours at $1.1 \cdot 10^{3} \mathrm{~Pa}$ (more than $10^{12} \mathrm{~L}$ ) increases $\delta_{\text {MAX }}$ by about 0.1 . With increasing $\mathrm{H}_{2} \mathrm{O}$ dose $\mathrm{E}_{\mathrm{MAX}}$ shifts to lower PE energy. 


\section{Influence of $\mathrm{H}_{2} \mathrm{O}$ exposure on the $\mathrm{SEY}$ of oxidised copper}

Copper samples, which were initially sputter-cleaned and then oxidised during exposure to pure oxygen, were afterwards exposed to pure $\mathrm{H}_{2} \mathrm{O}$.

$\delta_{\text {MAX }}$ of an oxidised copper sample increases by about 0.15 during a 15 days $\mathrm{H}_{2} \mathrm{O}$ exposure at $10^{3} \mathrm{~Pa}$. Such an exposure corresponds to the $\mathrm{H}_{2} \mathrm{O}$ dose accumulated after about 11 days air exposure (with an estimated $\mathrm{H}_{2} \mathrm{O}$ partial pressure of $1.4 \cdot 10^{3} \mathrm{~Pa}$, corresponding to $60 \%$ relative humidity at $20^{\circ} \mathrm{C}$ in the laboratory air). Thus, an air exposure increases the SEY much faster than similar doses of pure $\mathrm{H}_{2} \mathrm{O}$. This shows that the strong effect of an air exposure on the SEY can only be partly due to physisorption of water on the oxidised surface.

Nevertheless, water seems to play an important role in the process which increases SE emission during air exposures. Water rinsing of sputter-cleaned copper increases the SEY much faster than ordinary air exposures. $\delta_{\text {MAX }}$ of sputter-cleaned copper samples, which were exposed to air for $45 \mathrm{~min}$ and during this time dipped into distilled water for $10 \mathrm{~min}$, increased from 1.4 to 2.4 . $\delta_{\mathrm{MAX}}$ of an identical sputter-cleaned copper sample, which was not put into water during the $45 \mathrm{~min}$ air exposure, increased only to less than 1.6 .

\section{B Thermal treatments}

\section{Influence of bake-outs under vacuum on the SEY of as-received copper}

Figure 4 shows the influence of various bake-outs under vacuum on the SEY of asreceived copper.

At first the SEY of the as-received sample was measured. Afterwards the whole vacuum chamber was baked for 24 hours at $100^{\circ} \mathrm{C}, 200^{\circ} \mathrm{C}, 300^{\circ} \mathrm{C}$ and $350^{\circ} \mathrm{C}$ and after every step the SEY was again measured. Finally the SEY was measured after the sample was sputter-cleaned during a glow discharge. With increasing bake-out temperature the SEY decreases and $\mathrm{E}_{\mathrm{MAX}}$ shifts to higher PE energies.

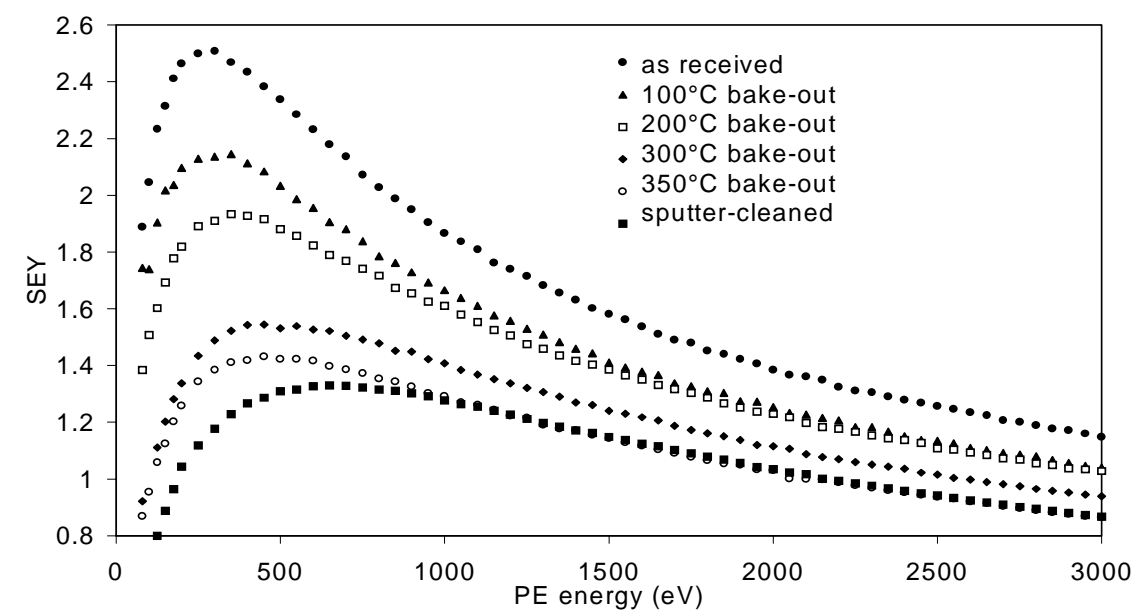

Figure 4: Influence of 24 hour bake-outs at various temperatures on the SEY of technical copper. With increasing bake-out temperature $\mathrm{SE}$ emission decreases and $\mathrm{E}_{\mathrm{MAX}}$ shifts to higher PE energy. 


\section{Influence of bake-outs under vacuum on the SEY of ex-situ sputter-cleaned copper}

A sputter-cleaned copper sample was exposed to air during 14 days. Afterwards the sample was baked 24 hours during chamber bake-out at $350^{\circ} \mathrm{C}$. As shown in Figure 5 this procedure decreases $\delta_{\mathrm{MAX}}$ to 1.2 (which is approximately the value of $\mathrm{Cu}_{2} \mathrm{O}$ ), $\mathrm{E}_{\mathrm{MAX}}$ shifts to $650 \mathrm{eV}$ and the SEY exceeds unity in the PE energy interval between $250 \mathrm{eV}$ and $1700 \mathrm{eV}$.

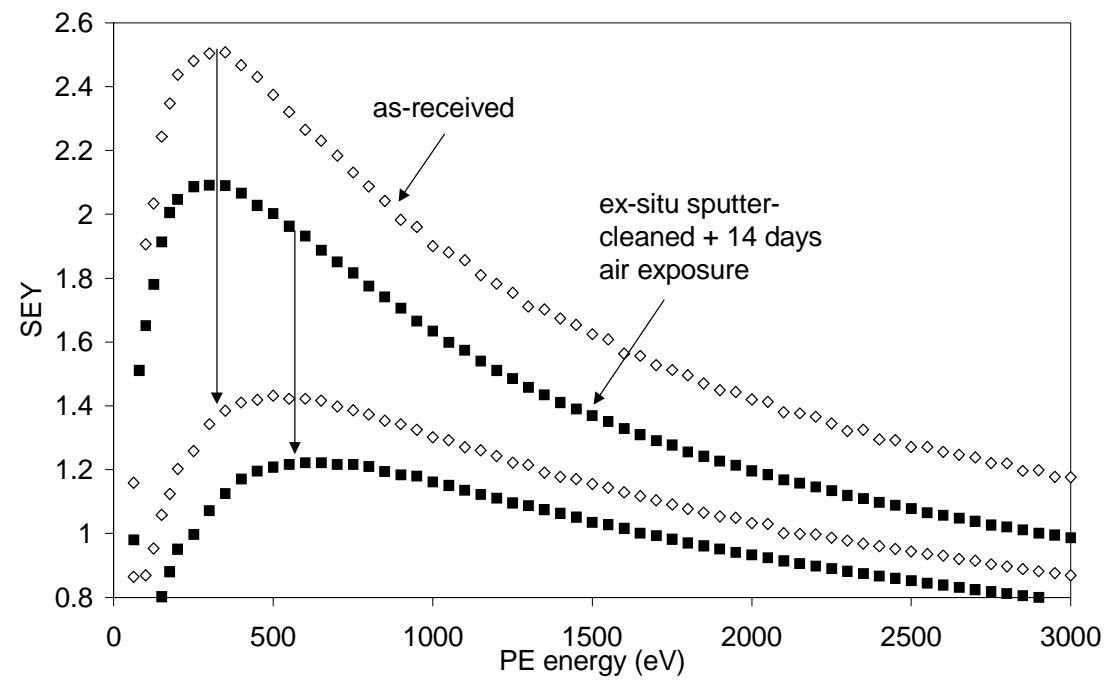

Figure 5: Different influence of a 24 hour $350^{\circ} \mathrm{C}$ bake-out on the SEY of as-received $\mathrm{Cu}$ and on ex-situ sputter-cleaned $\mathrm{Cu}$ which was exposed to air for 14 days.

Ex-situ sputter etching of copper prior to bake-outs under vacuum is thus advantageous in order to obtain a surface with a low SEY. After a $350^{\circ} \mathrm{C}$ bake-out of as-received copper $\delta_{\text {MAX }}$ is only reduced to about 1.4 and the PE energy range in which the SEY exceeds unity is $130 \mathrm{eV}-2150 \mathrm{eV}$.

Influence of air-baking followed by bake-out under vacuum on the SEY of asreceived copper

Air-baking of as-received copper samples was realised inside the vacuum chamber. Therefore, the vacuum system was first heated to the desired temperature $\left(150^{\circ} \mathrm{C}\right.$ and $350^{\circ} \mathrm{C}$ ) and then vented with ordinary laboratory air while the chamber was kept at the chosen bake-out temperature.

\section{Air-baking at $350^{\circ} \mathrm{C}$}

In Figure 6 the SEY of as-received copper after $5 \mathrm{~min}, 350^{\circ} \mathrm{C}$ air-baking and consecutive $350^{\circ} \mathrm{C}$ bake-out under vacuum is compared with the SEY of as-received copper after an ordinary $350^{\circ} \mathrm{C}$ bake-out under vacuum $\left(\delta_{\text {MAX }}\right.$ of as-received copper is about 2.5, as shown in Figure 4).

After 5 min air exposure at $350^{\circ} \mathrm{C}$ and a consecutive 6 hours $350^{\circ} \mathrm{C}$ bake-out under vacuum $\delta_{\mathrm{MAX}}$ is reduced to about 1.05 and the SEY exceeds unity in the PE energy interval between $300 \mathrm{eV}$ and $1000 \mathrm{eV}$. 


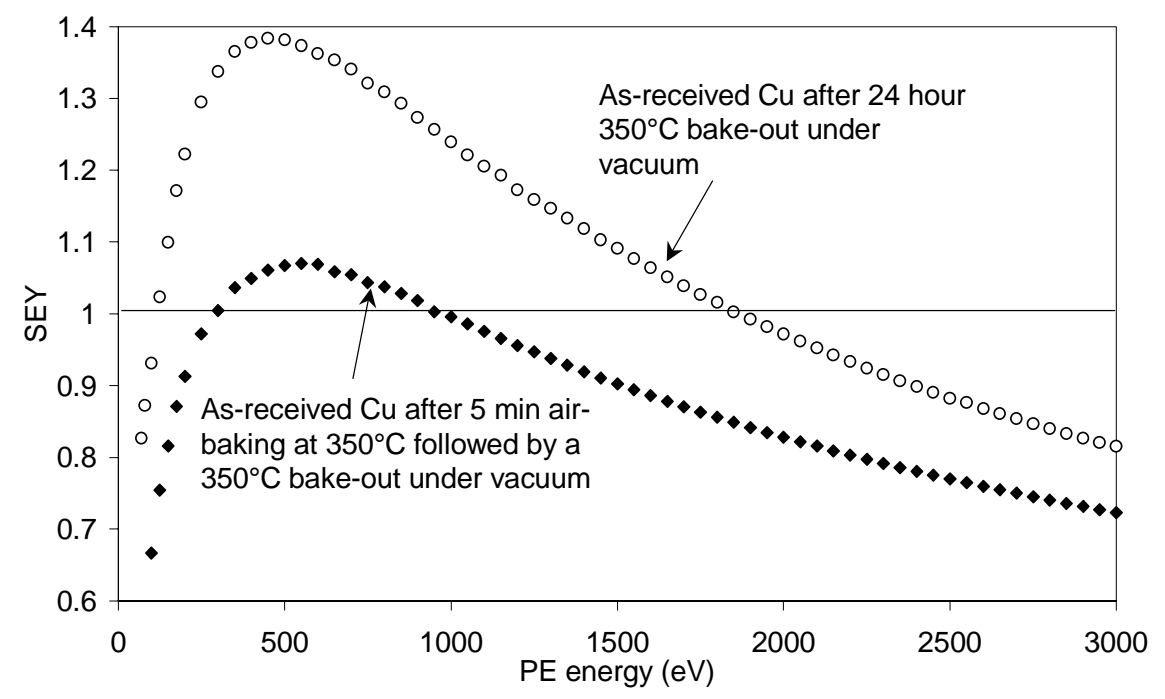

Figure 6: SEY of copper as received after 24 hours $350^{\circ} \mathrm{C}$ bake-out compared to the SEY of copper as received after 5 minutes air exposure at $350^{\circ} \mathrm{C}$ and 6 hours bake-out at $350^{\circ} \mathrm{C}$ under vacuum.

Auger electron spectroscopy (AES) sputter depth profiling, carried out at CERN, showed that the oxide layer after 5 minutes air-baking at $350^{\circ} \mathrm{C}$ is roughly $50 \mathrm{~nm}$ thick. The native oxide formed during air exposure at room temperature is approximately 1.6 $\mathrm{nm}$ thick. ${ }^{8}$ The copper surface is roughened during the $350^{\circ} \mathrm{C}$ air-baking, as can be seen in the two SE-images in Figure 8 (before air-baking) and Figure 9 (after air-baking).

\section{Influence of an air exposure on the SEY of air-baked copper}

The influence of an air exposure on the SEY of copper after the different treatments is strongly dependent on the PE energy as can be seen in Figure 7.

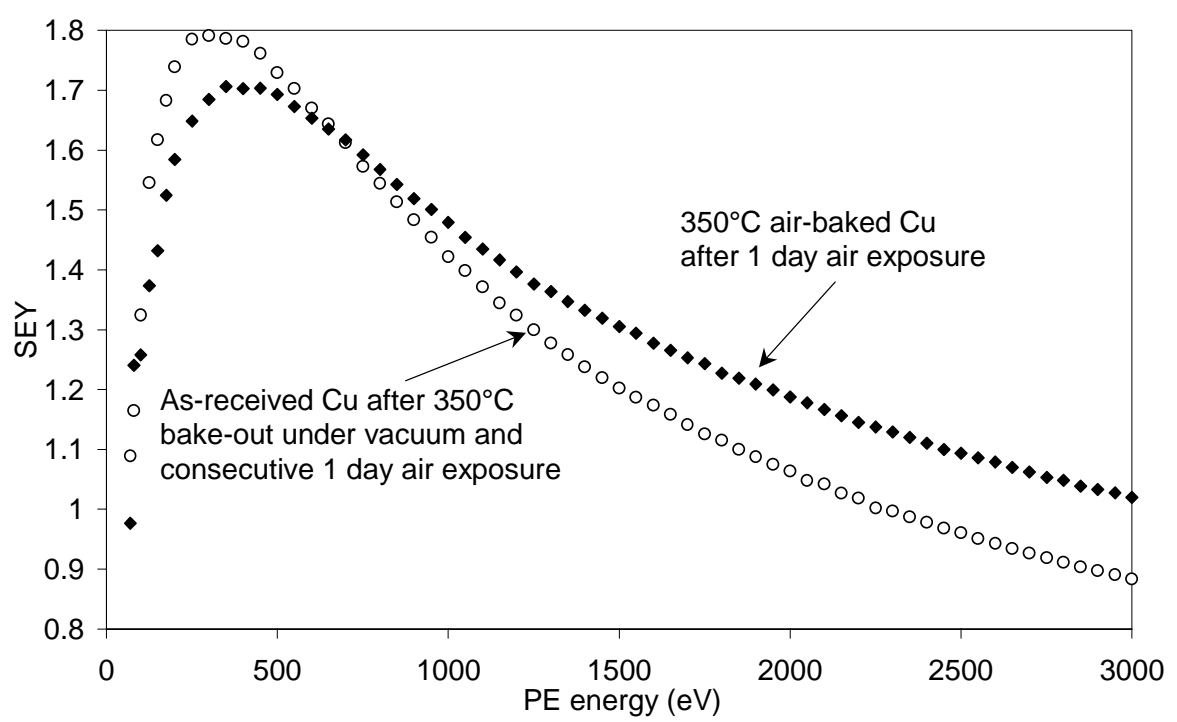

Figure 7: Influence of 1 day air exposure on the SEY of as-received copper and on $350^{\circ} \mathrm{C}$ airbaked copper. Both samples were baked at $350^{\circ} \mathrm{C}$ under vacuum before the 1 day air exposure. 
After an air exposure of one day at ambient temperature the SEY of air-baked copper becomes higher than the SEY of 'as-received' copper if PE energies exceed $650 \mathrm{eV}$ (both samples were baked at $350^{\circ} \mathrm{C}$ under vacuum before the 1 day air exposure).

\section{Air-baking at $150^{\circ} \mathrm{C}$}

In order to verify the effect of the sample temperature during the air-baking procedure as-received copper samples were exposed to air at $150^{\circ} \mathrm{C}$ during $30 \mathrm{~min}$ and afterwards the samples were baked 6 hours at $150^{\circ} \mathrm{C}$ under vacuum. After this procedure $\delta_{\mathrm{MAX}}$ is decreased from 2.5 to 1.5 and the SEY exceeds unity in the PE energy range between 80 $\mathrm{eV}$ and $1800 \mathrm{eV}$.

Thus, air-baking at $150^{\circ} \mathrm{C}$ has a much stronger effect on the SEY of as-received copper than an ordinary bake-out (see Figure 4) but it is less effective than air-baking at $350^{\circ} \mathrm{C}$.

\section{Discussion}

\section{A Influence of air exposures on the SEY of initially sputter-cleaned copper}

SE emission of clean metal surfaces increases after long air exposures. Copper, however, shows a special behaviour after short air exposures lasting only seconds or minutes. After such short exposures the SEY of initially clean copper decreases. A similar decrease of the SEY is observed when clean copper is exposed to pure oxygen.

The decrease of the SEY after $\mathrm{O}_{2}$ and short air exposures is mainly caused by the increasing thickness of the semiconductor $\mathrm{Cu}_{2} \mathrm{O}$, which has a lower SEY than pure $\mathrm{Cu}$, whereas the role of the work function (WF) seems to be minor.

It is known that the WF of atomically clean $\mathrm{Cu}$ increases by about $0.3 \mathrm{eV}$ after $10 \mathrm{~L} \mathrm{O}_{2}$ exposure, which corresponds to one monolayer absorbed oxygen ${ }^{7}$, and after further exposure the WF increases only slightly. Since significant changes of the SEY were only observed after more than $100 \mathrm{~L} \mathrm{O}_{2}$ exposure and the SEY continued to decrease with increasing oxygen dose up to $10^{9} \mathrm{~L}$, one can conclude that the influence of the WF on the SEY of sputter-cleaned copper is not very strong. Generally, the influence of the WF on SE emission of metals is much smaller than it is on other electron emission processes like photo, thermionic or field emission, mainly because the mean energy of SE is comparatively high. ${ }^{6}$

After the fast surface oxidation a comparatively slow process increases the SEY steadily until, after approximately 8 days of atmospheric exposure, $\delta_{\text {MAX }}$ reaches values higher than 2. Water vapour seems to play an important role in the process which slowly increases the SEY.

X-ray photoelectron spectroscopy (XPS) measurements of $\mathrm{Cu}_{2} \mathrm{O}$ have shown that pure water vapour exposure has no visible effect on $\mathrm{Cu}_{2} \mathrm{O} \cdot \mathrm{O}_{2} / \mathrm{H}_{2} \mathrm{O}$ mixtures, however, involve surface hydroxilation of $\mathrm{Cu}_{2} \mathrm{O}$. ${ }^{9}$ Since pure $\mathrm{H}_{2} \mathrm{O}$ exposure has comparatively little effect on SE emission of copper but $\mathrm{H}_{2} \mathrm{O}$ in the presence of the other gases in air has a strong effect, hydroxide formation may be important for the drastic SE emission increase of metals after long air exposures. 


\section{B Influence of bake-outs under vacuum on the SEY of technical copper}

SE emission of technical metal surfaces can be reduced by in-situ bake-outs. A 24 hour bake-out at $350^{\circ} \mathrm{C}$ of as-received copper decreased $\delta_{\text {MAX }}$ from 2.5 to about 1.4 , which is close to the value obtained for sputter-cleaned copper. However, the PE energies $\mathrm{E}_{\mathrm{MAX}}$ and $\mathrm{E}_{1}$ of as-received copper after the $350^{\circ} \mathrm{C}$ bake-out are significantly lower than $\mathrm{E}_{\mathrm{MAX}}$ and $E_{1}$ of sputter-cleaned copper. This shift of $E_{\mathrm{MAX}}$ and $\mathrm{E}_{1}$ to lower PE energies is typical for contaminated surfaces.

In order to limit multipacting the PE energy interval in which the SEY exceeds unity should be as small as possible. A sputter-cleaned copper surface is hence less likely to cause multipacting problems than a technical copper surface after a 24 hours $350^{\circ} \mathrm{C}$ bake-out, even if $\delta_{\text {MAX }}$ values of both surfaces are similar.

Ex-situ cleaning of as-received copper by sputter etching is advantageous in order to obtain a low SEY after consecutive in-situ bake-outs. A $350^{\circ} \mathrm{C}$ bake-out of copper which was sputter-cleaned before a 14 days air-exposure decreased $\delta_{\text {MAX }}$ to about 1.2, which is lower than the value of pure copper.

\section{$C$ Influence of air-baking with consecutive bake-out under vacuum on the SEY of as-received copper}

The oxidation of copper at $350^{\circ} \mathrm{C}$ in air followed by a bake-out under vacuum effectively reduces SE emission. This procedure is thus efficient in removing the surface contamination, which causes the high SEY of as-received copper.

In addition the $350^{\circ} \mathrm{C}$ air-baking roughens the copper surface as can be seen in the two scanning electron microscope images shown in Figure 8 (before air-baking) and Figure 9 (after air-baking). Very rough surfaces emit less SE than smooth surfaces because emitted SE can re-enter the surface and may not escape again. ${ }^{6}$

Most metal oxides are insulators, which have much higher SEY values than the corresponding pure metals (mainly due to the comparatively large escape depth of SE in insulators). An increased thickness of such oxide layers would therefore increase SE emission.

However, cuprous oxide $\left(\mathrm{Cu}_{2} \mathrm{O}\right)$, which is the oxide formed when copper is exposed to air at ambient temperature, is a semi-conductor, which has a lower SEY than pure copper. ${ }^{6}$ Hence, an increased $\mathrm{Cu}_{2} \mathrm{O}$ layer thickness can decrease SE-emission, provided that the escape depth of SE is larger than the native oxide layer thickness. The native oxide layer thickness formed during air exposure of copper at ambient temperature has a thickness of about $1.6 \mathrm{~nm}^{8}$ (determined by angle resolved X-ray photoelectron spectroscopy XPS).

XPS measurements carried out at CERN show that the oxide present on the $350^{\circ} \mathrm{C}$ airbaked copper samples after $350^{\circ} \mathrm{C}$ bake-out under vacuum and air exposure at ambient temperature consists mainly of cuprous oxide. Only traces of $\mathrm{CuO}$ were detected.

However, it is reported that at $350^{\circ} \mathrm{C}$ the air-formed copper oxide consists of both, $\mathrm{Cu}_{2} \mathrm{O}$ and $\mathrm{CuO}^{8}$ The reason for this contradiction may be caused by uncertainties of the 
sample temperature during air-baking (only the vacuum chamber temperature was measured and kept at $350^{\circ} \mathrm{C}$ during the air exposure).

Exposing air-baked copper to air at ambient temperature results in an increased SE emission. This effect is particularly strong at high PE energies. Some kind of in-situ cleaning of air-baked copper, e.g. a bake-out under vacuum, is required in order to reach a $\delta_{\text {MAX }}$ below 1.1 .

\section{Conclusion}

The problem of multipacting in copper accelerator vacuum equipment can be strongly enhanced by air exposures. Unavoidable air exposures should be kept as short as possible since the SEY of initially clean copper increases with air exposure time.

Bake-outs under vacuum are more effective in reducing SE emission if the as-received copper surfaces are cleaned by ex-situ sputter etching before the in-situ bake-out.

Heating copper in air prior to an in-situ bake-out is a simple method to produce large uniform surfaces with reduced SE emission. The long term stability of such strongly oxidised copper surfaces remains to be studied. 


\section{Appendix}

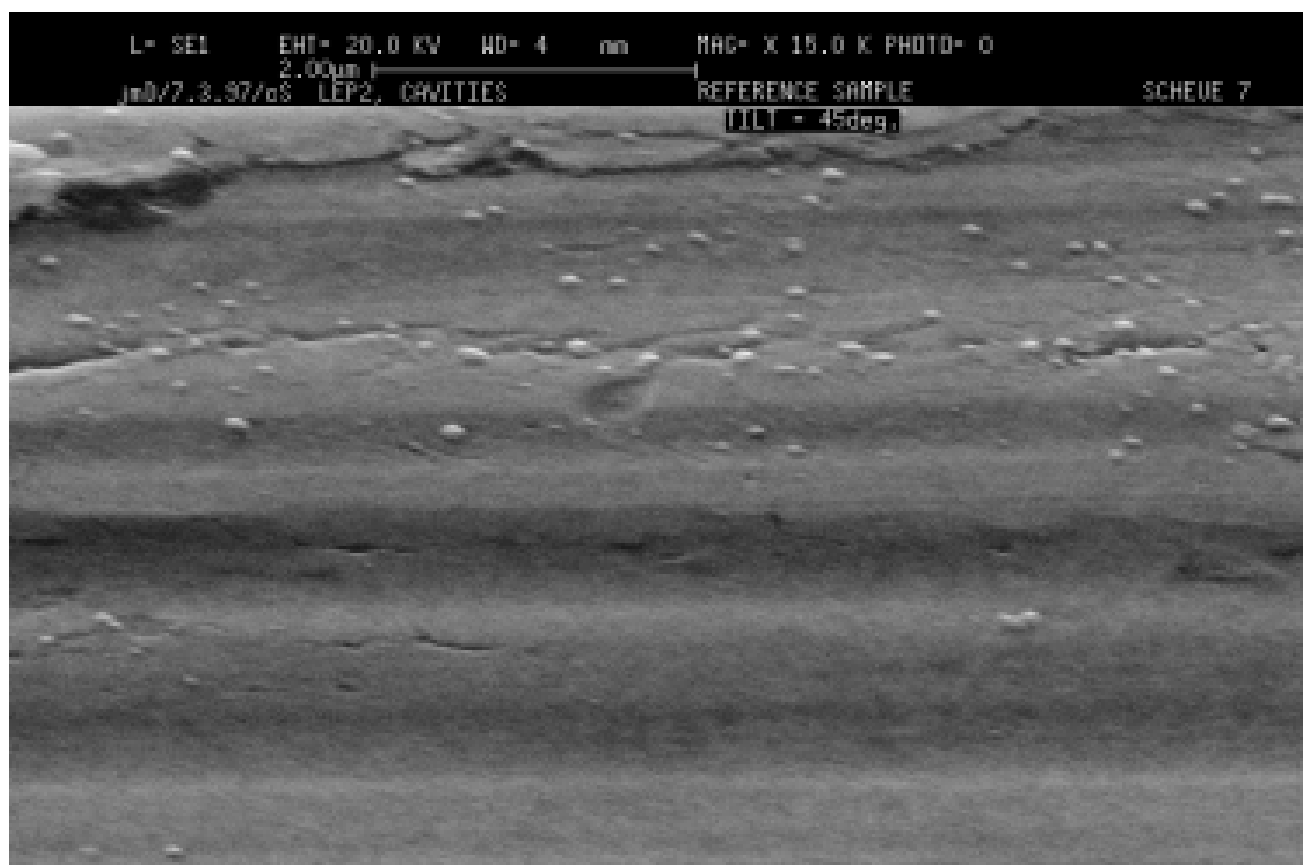

Figure 8: Secondary electron image of copper as-received (magnification $=15000)$.

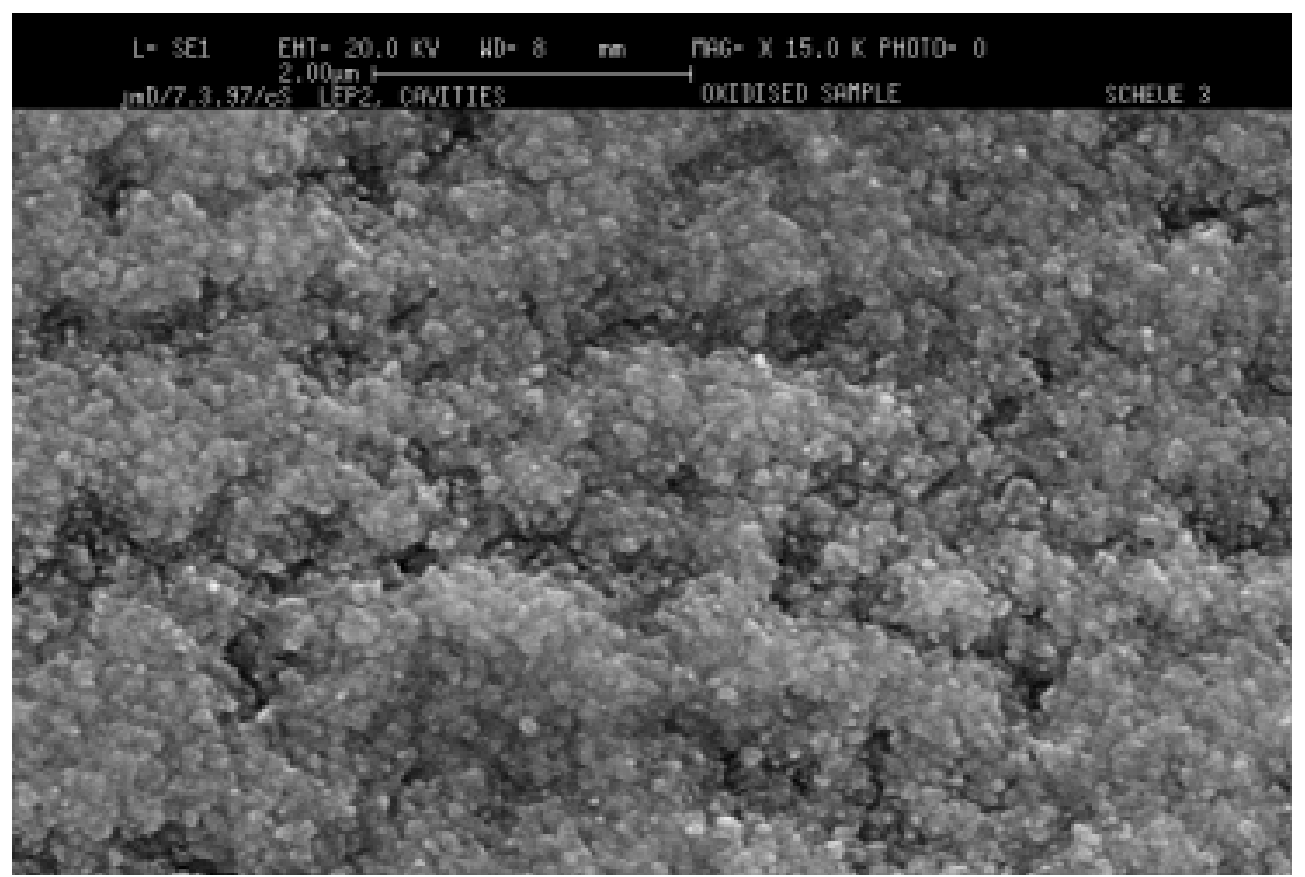

Figure 9: Secondary electron image of copper after $5 \mathrm{~min}$ air exposure at $350^{\circ} \mathrm{C}$ and $350^{\circ} \mathrm{C}$ bake-out under vacuum (magnification $=15000$ ). 


\section{Acknowledgements}

We are grateful to Mauro Taborelli for fruitful discussions and to Jean-Luc Dorier for proposing the air-baking of copper.

\section{References}

\footnotetext{
${ }^{1}$ H. Lengeler, in CERN Accelerator School Fifth General Accelerator Physics Course 2, edited by S. Turner, 791, (1994)

2 O. Gröbner,, CERN, LHC Project Report 127, (1997)

${ }^{3}$ R.E. Davies, J.R. Dennison, J. Spacecraft 34, 571, (1997)

${ }^{4}$ H.J. Hopman, J. Verhoeven, J.J. Scholtz, R. Fastenau, Appl. Surf. Sci. 111, 270, (1997)

${ }^{5}$ C. Benvenuti, G. Canil, P. Chiggiato, P. Collin, J. Guérin, S. Ilie, D. Latorre, K.S. Neil, Vacuum 53, 317, (1999)

${ }^{6}$ H. Bruining, Physics and Applications of Secondary Electron Emission, (Pergamon Press, London, 1954), pp. 39-75

${ }^{7}$ L.F. Wagner, W.E. Spicer, Surf. Sci. 46, 301, (1974)

${ }^{8}$ S.K. Chawla, B.I.Rickett, N. Sankarramn, J.H. Payer, Corros. Sci. 33, 1617, (1992)

${ }^{9}$ T. Robert, M. Bartel, G. Offergeld, Surf. Sci. 33, 123, (1972)
} 